\title{
Corrigendum
}

\section{Time trends in socio-economic inequalities in stunting prevalence: analyses of repeated national surveys - CORRIGENDUM}

\author{
María Clara Restrepo-Méndez, Aluísio JD Barros, Robert E Black and Cesar G Victora
}

First published online 11 February 2016

doi:10.1017/S1368980014002924. Published online by Cambridge University Press 18 December 2014.

The acknowledgements in this paper should have read:

\section{Acknowledgements}

Financial support: These analyses were supported by grants from the Bill and Melinda Gates Foundation to the Lancet Nutrition Series 2013 (through the Institute for International Programs at Johns Hopkins Bloomberg School of Public Health), the Countdown to 2015 Initiative (through the Federal University of Pelotas via the US Fund for UNICEF) and Wellcome Trust [Grant Number: 101815/Z/13/Z]. The funders had no role in the design, analysis or writing of this article.

\section{Reference}

Restrepo-Méndez MC, Barros AJD, Black RE \& Victora CG (2015) Time trends in socio-economic inequalities in stunting prevalence: analyses of repeated national surveys. Public Health Nutrition 18, 2097-2104. doi: 10.1017/S1368980014002924. 